\title{
Cardiovascular profile of defensive hostile women in a real stressful situation
}

\author{
Francisco Palmero ${ }^{1 *}$, Cristina Guerrero ${ }^{2}$ and Ricardo Gorayeb ${ }^{3}$ \\ 1 University Jaume I of Castellón (Spain). \\ 2 University of Cádiz (Spain). \\ 3 University of Sao Paulo (Brazil).
}

\begin{abstract}
Título: Perfil cardiovascular de mujeres hostiles defensivas en una situación de estrés real.

Resumen: El objetivo del presente estudio ha sido analizar el impacto de la hostilidad defensiva sobre la respuesta cardiovascular en una situación estresante. Mediante la medición de la frecuencia cardiaca, la presión sistólica y la presión diastólica, a través de las tres fases del experimento (adaptación tarea y recuperación), hemos analizado la evolución de la respuesta cardiovascular minuto a minuto a lo largo de toda la sesión experimental, para comprobar si la hostilidad defensiva influye sobre la función cardiovascular. Se utilizaron dos escalas: la Escala Compuesta de Hostilidad del inventario de hostilidad de Cook-Medley y la escala de deseabilidad social de MarloweCrowne. Basándonos en las puntuaciones de estas escalas, se formaron cuatro grupos (alta hostilidad-alta defensividad, alta hostilidad-baja defensividad, baja hostilidad-alta defensividad, y baja hostilidad-baja defensividad). La situación de estrés utilizada en la tarea fue un examen real. La hipótesis propuesta fue que la respuesta cardiovascular, la activación y la recuperación, minuto a minuto, serían mayores en las mujeres hostiles defensivas, con un perfil de evolución caracterizado por el mantenimiento o la sensibilización y la recuperación lenta. Los resultados muestran que las personas hostiles defensivas presentan los valores más altos en las variables fisiológicas registradas, así como perfiles menos adaptativos.
\end{abstract}

Palabras clave: Respuesta cardiovascular; hostilidad; defensividad; estrés.

\section{Introduction}

The interest in studying the relationship between psychosocial factors and the risk of cardiovascular disease (CVD) has increased because of both the increasing number of deaths caused by these diseases in western and developing countries and the inability of the classic risk factors to explain its occurrence and prevalence (Everson-Rose, \& Lewis, 2005). According to the World Health Organization, estimated 17.3 million people died from CVDs in 2008 , over $80 \%$ of CVD deaths took place in low- and middle-income countries, and by 2030, almost 23.6 million people will die from CVDs (World Health Organization, 2013).

There is extensive literature on psychological factors, such as hostility, anger, stress, depression, anxiety and CVDs (Brydon et al., 2010; Chida, \& Steptoe, 2009; Jorgensen, \& Kolodziej, 2007; Vella, \& Friedman, 2009). As noted in a previous work (Guerrero, \& Palmero, 2010; Palmero, \& Guerrero, 2012), psychosocial factors have gained importance to such an extent that research has been able to explain the mechanisms of action of these variables on cardiovascular disease. The results obtained in various research works have confirmed the relationship between psychosocial factors and the atheromatous plaque, which constitutes the basic injury occurring in cardiovascular disease. The mechanisms involved in its formation, which are mechanical and

* Dirección para correspondencia [Correspondence address]:

F. Palmero. University Jaume I, Av. Sos Baynat, s/n. Campus Riu Sec. 12071. Castellón de la Plana (Spain). E-mail: palmero@uji.es
Abstract: The main objective of this study was to analyze the impact of defensive hostility on cardiovascular response in a stressful situation. By measuring three of the most commonly used cardiovascular indexes (heart rate, systolic blood pressure and diastolic blood pressure) over three experimental phases (adaptation, task and recovery), the evolution of cardiovascular response was analyzed minute by minute throughout the entire experimental session, to check if the defensive hostility influences the cardiovascular function. Two scales were used: the Cook-Medley Composite Hostility Scale and the Marlowe-Crowne Social Desirability Scale. Based on the scores on these scales, there were formed four groups (high hostility and high defensiveness, high hostility and low defensiveness, low hostility and high defensiveness, and low hostility and low defensiveness). The stressful situation which was used in the task phase was a real academic examination (exam of the Psychology degree). The hypothesis was that cardiovascular response, activation and recovery, minute by minute, will be greater in hostile defensive women, with an intra-phase evolution profile characterized by maintenance or sensitization and slow recovery. Results show that defensive hostile individuals present the highest values in the physiological variables recorded, and less adaptive profiles.

Key words: Cardiovascular response; hostility; defensiveness; stress. chemical factors, are seriously affected by psychosocial processes, and especially by the stress response. In these processes, emotions cause a faster heart rate and higher blood pressure, leading to increased blood flow and turbulence. In addition, there is a mobilization of lipids which exceeds the body's metabolic requirements, and which facilitates aggregation to artery walls and heart tissue. This relationship between psychosocial factors and cardiovascular disease has received the generic name of "Hypothesis of the cardiovascular reactivity", and has been supported by various prospective studies (Steptoe, Cropley, \& Joekes, 2000). Research has shown that individuals who tend to display strong responses and reactivity are at increased risk of cardiovascular disease.

In order to better understand the approach, it is worthwhile to refer to the profiles described by Kelsey (1993) on which this investigation is based. There are different ways to respond physiologically to stressful events, which depends on external factors (situational) and internal factors (e.g. personality variables). In this regard, and from the classic proposal of Kelsey, it may be noted three response patterns, which reflect corresponding profiles associated with different forms of reaction to stressful events. a) Habituation pattern, when someone perceives a situation as potentially threatening or novel, occurs an increase in cardiovascular reactivity. After an exposure time in such a situation, and after that initial increase, there is a phenomenon of habituation, during which it can be seen a progressive decrease of the initial values. This phenomenon is considered essential in the 
process of adaptation and regulation of humans and nonhuman animals, demonstrating the ability of self-regulation in the organism, that is, it can be activate to deal with a potentially dangerous or threatening situation and, in turn, is able to return to baseline (BL) once the situation has gone or is under control. b) Sensitization pattern, when the individual responds to a stressor stimulus with a high cardiovascular reactivity, similar to the previous pattern but without the occurrence of habituation. Instead, it produces a progressive increase in reactivity over the situation. It shows an organism's inability to return to BL, which is highly detrimental to the heart muscle and overall health. c) Constant pattern, it occurs an initial increase, similar to that of the other two patterns, but with no habituation or sensitization. This increase remains constant throughout the stress. Thus, this pattern is also maladaptive, since there is no preparation behavior, being it essential in the adaptation to the environment (Cannon, 1932), or has the ability to return to BL levels.

Only the first of these patterns is adaptive, decreasing when the individual cardiovascular reactivity to stressful events faced long periods of time. The initial increase in activation allows for better coping with the situation, and the subsequent decline after a period of time is necessary to avoid damaging the body and maintain homeostasis (Palmero, Breva, \& Espinosa, 1994; Palmero, \& Guerrero, 2012).

It seems clear that dysfunction risk is associated with higher scores when an individual is faced with a stressful situation. But there is another factor that may be associated with the eventual dysfunction: the slow recovery. That is, a profile characterized by the absence of habituation involves too long a time in which the body is exposed to harmful substances secreted with the stress response: catecholamines and cortisol. Therefore, the second and third patterns are maladaptive, because there is no habituation.

Among the psychosocial factors that may influence the development, maintenance, and progression of cardiovascular disease, hostility as possible risk factor has received substantial empirical support in last years. Thus, in recent studies (Olson et al., 2005; Chida, \& Steptoe, 2009; Shimbo et al., 2009; Sloan et al., 2010), the authors propose that high scores on hostility can be a good predictor of future cardiovascular events in healthy individuals, ie. individuals without a history of cardiovascular disease events, particularly among women. That is: a hostility-heart disease relationship is proposed. Even in patients with cardiovascular disease, the existence of high hostility scores can be considered as a good predictor of survival time of patients: high scores are associated with lower survival (Boyle et al., 2004; Denollet, Gidron, Vrints, \& Conraads, 2010). Hostility also influences recovery after stress. So, Hutchinson, and Ruiz (2011), using systolic blood pressure as cardiovascular parameter, found that women high in Neuroticism showed less recovery following hostile interactions and greater recovery following friendly interactions.

Some studies do not find this important effect of hostility on the reactivity (Hernandez, Larkin, \& Whited, 2009). In a way, this kind of results leads to keep looking for the true role of hostility in cardiovascular function. The authors note that hostility is not always associated with exaggerated cardiovascular reactivity to stress, and the influence of various moderating factors should be considered in elucidating this relation. However, it should be noted that in this work only systolic blood pressure was taken into account. Perhaps, it was relevant to consider also other cardiovascular variables.

In recent years, the likely role of defensive hostility has been suggested (Larson, \& Langer, 1997; Shapiro, Goldstein, \& Jamner, 1995), noting that it would be more convenient to go deeper into the study of hostility, including defensiveness as a moderating factor (Brosschot, Gerin, \& Thayer, 2006). In this way, nowadays, research has focused on defensive hostility (high hostility and high defensiveness) as one of the psychosocial factors with more weight and empirical support in its relationship with cardiovascular disease (Helmers, \& Krantz, 1996; Jorgensen, \& Thibodeau, 2006; Larson, \& Langer, 1997; Vella, \& Friedman, 2007). The trait of defensive hostility reflects an approach-avoid conflict between the desire for social approval and distrust of those who can provide such support (Jamner, Shapiro, Goldstein, \& Hug, 1991).

People with defensive hostility show greater cardiovascular response during the task phase that other groups can be formed when combining hostility and defensiveness variables (Larson, \& Langer, 1997). Particularly, subjects with defensive hostility show higher blood pressure values in stressful situations, although more recently has been observed that the systolic index better reflects the high activation (Mente, \& Helmers, 1999). Likewise, patients who obtain high scores for defensive hostility showed a higher cardiac response, higher rates of ischemia during a mental stress situation, greater damage by infusion and a longer duration of ischemia during daily activities (Helmers et al., 1995).

Moreover, in recent works, our team (Guerrero, \& Palmero, 2010; Palmero, \& Guerrero, 2012) has found that defensive hostile individuals take longer to recover from the stress response. This highlights the importance of considering recovery phase in the laboratory experimental research, since it provides vital information on restoring physiological parameters. Indeed, when the individual is faced with a stressful situation, their response systems are activated. The sympathetic adrenomedullary system and pituitary adrenocortical system release adrenaline and noradrenaline and cortisol, respectively. These substances are necessary for a good response to stress. However, if they remain in the blood long time, can cause adverse health effects. This is the theoretical importance of recovery from stress. An excessively long recovery phase allows these substances remain longer than recommended in the blood, increasing the risk of cardiovascular dysfunction. Therefore, the recovery phase is a basic and essential element in the detection of the future dysfunctions risks. To analyze the recovery phase is an aspect that has not been widely studied, and, as indicated by some authors (Anderson, Linden, \& Habra, 2005; Guerrero, 
\& Palmero, 2010; Palmero, \& Guerrero, 2012), we believe that may be one of the important aspects in the detection of cardiovascular disease risk.

The general objective of this study was to analyze the relationship between defensive hostility and cardiovascular responses (HR, SBP and DBP), using a continuous psychophysiological assessment approach. That is, to analyze the evolution of the cardiovascular variables throughout three experimental phases: adaptation, task, and recovery, considering also the minute by minute analysis within each phase. This general objective was broken down into the following sub-objectives:

First, to establish the functional significance of the overall profiles in the four groups formed by the hostility and defensiveness variables, considering each of the three cardiovascular variables along the three phases of the experiment. Second, to establish the functional significance of cardiovascular profiles in each of the four groups when considering the evolution of the studied parameters within each phase.

The general hypothesis was that hostile defensive individuals will present a less adaptive profile throughout the three phases. The following corollaries emerge from this hypothesis:

1. Defensive hostile individuals will present greater activation in the task phase and a slower recovery profiles.

2. Defensive hostile individuals will present an intra-phase evolution of the values corresponding to the three recorded variables characterized by maintenance, sensitization, and slow recovery.

2.1.During the adaptation and task phase, the hostile defensive individuals' profile will be characterized by maintenance or sensitization.

2.2.During the recovery phase, the hostile defensive individuals' profile will be characterized by slow recovery.

\section{Method}

\section{Participants}

The initial simple was formed by 137 participants, male and female students at University Jaume I de Castellón (Spain). Eleven participants were eliminated from the investigation to be taking medication, or have slept very little time last night. The sample consisted of 126 students: 110 women and 16 men. Although the study included all participants, in this paper we present the data for the sample of 110 women, hoping to continue to expand the sample of men to analyze the data. The final sample consisted of 110 female students. All were healthy volunteers, aged between 18 and 30 years (mean $=20.19, S D=1.38)$. All participants received course credit for their collaboration.

The criteria used to form the groups were the scores obtained with both the Composite Hostility Scale (Cook, \& Medley, 1954) and the Social Desirability Questionnaire
(Crowne, \& Marlowe, 1960). As used in other studies (Larson, \& Langer, 1997) the median of the sample was the cutoff point to classify participants as "high" or "low" in each variable: high hostility $>11$; low hostility $<11$; high defensiveness $>14$; low defensiveness $<14$. Therefore it were excluded the participants with exactly the median values, in order to better differentiate the groups. Four groups were formed: high hostility and high defensiveness (DH), high hostility and low defensiveness $(\mathrm{HH})$, low hostility and high defensiveness (Def), and low hostility and low defensiveness (LH).

The number of participants in each of the four resultants groups were the following: Defensive Hostility (DH, $n=$ 21), High Hostility ( $\mathrm{HH}, n=36)$, Defensive (Def, $n=35$ ) and, Low Hostility (LH, $n=18)$.

\section{Instruments}

Cardiovascular responses were measured with the data acquisition MP150 system and the NIBP100A amplifier (Biopac Systems). These cardiovascular parameters were recorded continuously and noninvasively.

For the measurement of cardiovascular variables the software "AcqKnowledge", included in the Biopac system, was used.

To program the pattern of stimuli presentation, the "SuperLab 4.0" (Cedrus Corporation, 2008)

Hostility was measured with the Hostility Inventory Scale (Cook, \& Medley, 1954). This instrument consists of 50 alternative choice item (true or false) extracted from the MMPI. In this study, the Composite Hostility Score (Chost) was used. Chost consists of 27 items distributed in three subscales: cynicism (13), hostile feelings (5) and aggressive responses (9), as it has been found that provides greater capacity than the Ho scale as a whole to predict cardiovascular reactivity (Barefoot, Dodge, Peterson, Dahlstrom, \& Williams, 1989; Christensen, \& Smith, 1993).

Defensiveness was measured with the Spanish version (Ávila \& Tomé, 1989) of the Social Desirability Questionnaire (Crowne, \& Marlowe, 1960). Specifically, this Spanish version, known as "Personal Questionnaire Reactions" (CRP), consists of 33 items of choice alternatives (true or false) that reflect socially desirable behaviors and cognitions.

A real academic exam was used as a situation of stress. This situation represents a real mental stress task for students. More specifically, it was used a partial exam of the degree of Psychology (core subject). The test format was 20 objective questions with four possible answers for each question (1, 2, 3, and 4), of which only one was correct. In this test, the errors penalize. The resulting score was obtained using the following formula: A - (e/k-1), where " $k$ " is the number of alternatives. Thus, we could correct the effects of randomness in the response. All analyses were carried out with the SPSS statistical program (v. 19). 


\section{Procedure}

Classroom were informed about the research, and students who agreed to participate voluntarily completed Ho and CRP inventories (for the purposes of this research, only the Ho Chost scale was used). Two days later, the participating students knew the day and time that they had to go to the laboratory for examination with psychophysiological recording. On arrival to laboratory, each student was attended by a team member, it was always the same person who received the students, and who explained the conditions of the experiment.

After signing the informed consent form (this study is part of a largest research project which has already been submitted and approved by the University Ethics Committee), each participant filled out a questionnaire with their personal data, the hours she had slept the night before, some health matters and medicine taken.

Then, they went into the experimental cabin, where a sensor was placed on the wrist of their non-dominant arm. The experimental room was a Faraday cabin, soundproof and prepared for psychophysiological recordings, with control of temperature, humidity and lighting. In the cabin, there was a comfortable chair, in which sat the participant. In front of him was a screen, on which were projected examination questions and instructions. In addition, the cabin was connected to the control room (where the experimenter was located) by an audio system, which allowed to hear the participant answers to exam questions. The psychophysiological variables, heart rate (HR), systolic blood pressure (SBP) and diastolic blood pressure (DBP), were recorded in their tonic dimension throughout the entire experimental session.

While participants were prepared for the recording session, the experimenter provided the instructions to answer exam questions. When the participant had no doubt, the experimenter left the cabin, leaving the participant alone, and the recording session began.

\section{Recording Session}

All recording sessions took place in the Emotions and Cardiovascular Psychophysiology, at the university, performing morning from 9:00 to 14:00 hours. Before the start of the psychophysiological recording session, the experimenter told the participants to try to relax and not think about anything, while measuring equipment was adjusted. The recording session lasted 40 minutes, consisting of three distinct phases: adaptation, task and recovery. (a) Adaptation phase (10 $\mathrm{min})$ : there was no stimulus. The purpose of this period was for participants to become familiar with the environment. The psychophysiological variables were recorded to establish the baseline (BL), with the aim of obtaining the participants' usual levels under rest conditions, or, at least, a similar level.

(b) Task phase $(20 \mathrm{~min})$ : the 20 stimuli that formed the experimental task were presented, consisting of an objective test of 20 questions about the course contents, with four alternative answers. The stimuli were separated by a oneminute period, and the duration of this phase was therefore 20 minutes. Each stimulus was exposed for 30 seconds, after which there was a period of another 30 seconds with black screen until the next stimulus appeared. The participant had to answer out loud the number of the chosen alternative in each question $(1,2,3$, or 4$)$, or remain silent if he chose not to respond. Furthermore, the length in response to a question ended at the moment when the next question appeared.

(c) Recovery phase (10 min): no stimulus was presented. This phase was included to see how these variables recovered their usual levels after the stressful situation.

\section{Results}

\section{Statistical Analysis}

An analysis of variance (ANOVA) was carried out in order to compare the four experimental groups.

First, a mixed factorial design 4 (groups) x 3 (phases), with repeated measures on the phase. Moreover, within each phase, a mixed factorial design was used. In the adaptation phase, 4 (groups) x 10 (minutes of phase), with repeated measures on the minutes, was used. The same was done in the recovery phase: a mixed factorial design 4 (groups) x 10 (minutes of phase), with repeated measures on the last factor. In the task phase, a mixed factorial design 4 (groups) $x$ 20 (minutes of phase), with repeated measures on the phase factor minutes, was used.

The first of the objectives in our work was to establish the functional significance of the overall profiles in the four groups formed by the hostility and defensiveness variables, considering each of the three cardiovascular variables along the three phases of the experiment. An ANOVA with a mixed design 4 (groups DH, HH, Def and LH) x 3 (phases of the experiment), with repeated measures for the variable phase, was used.

As to the heart rate, Figure 1 shows the averaged values for each phase of the four groups. 


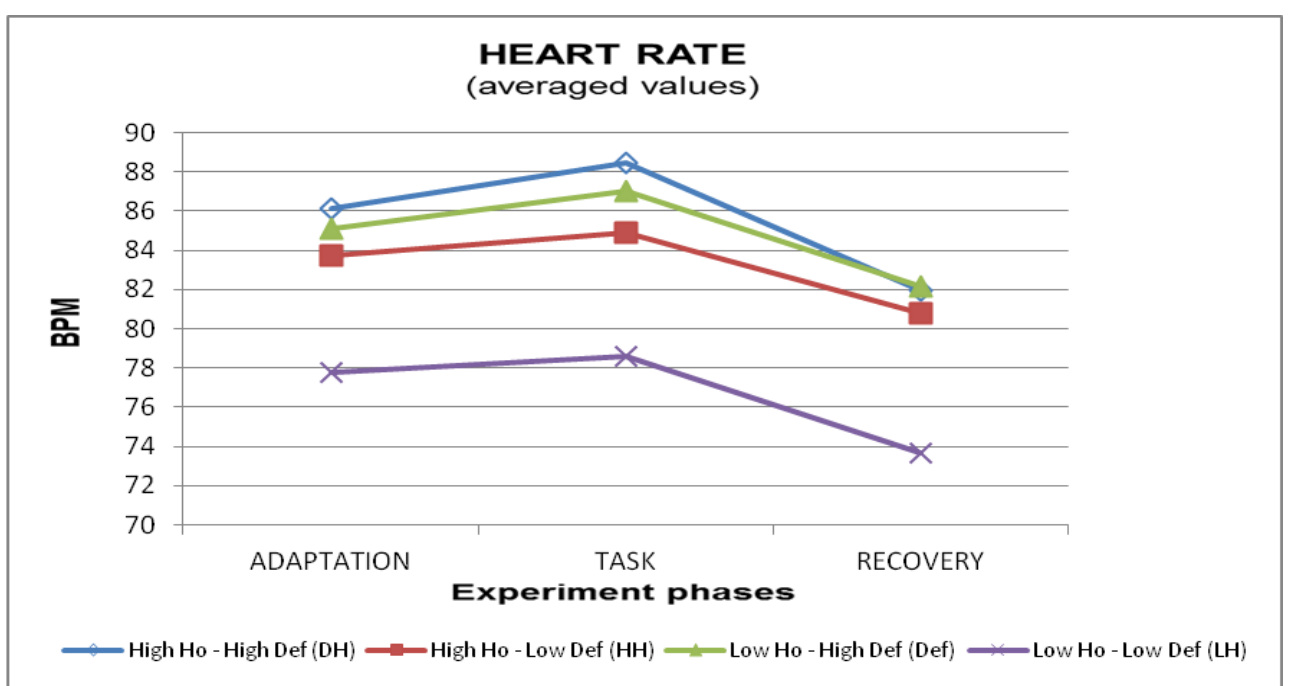

Figure 1. Heart rate averaged values obtained by the four groups in the three phases of the experiment.

The analysis done made it possible to locate the existence of significant differences in the variable phase $\left(F_{2,212}=59.68, p<.0001\right)$. To define the nature of these differences more accurately, a univariate analysis specific to each phase was conducted, but there were no significant differences. To establish the functionality of the psychophysiological profiles, analyses intra was conducted to locate any differences between the average values for the three phases in each experimental group. The intra-specific analyses, $t$-test, reveals significant differences in the four groups during the different phases. In the DH group, between adaptation and recovery $\left(T_{20}=2.365, p<.028\right)$, and between task and recovery $\left(t_{20}=6.902, p<.0001\right)$. In the HH group, between adaptation and recovery $\left(\mathrm{t}_{35}=3.831, p<.001\right)$, and between task and recovery $\left(t_{35}=5.746, p<.0001\right)$. In the Def group, between adaptation and task $\left(t_{34}=-2.766, p<.009\right)$, between adaptation and recovery $\left(t_{34}=3.682, p<.001\right)$, and between task and recovery $\left(t_{34}=6.230, p<.0001\right)$. In the LH group, between adaptation and recovery $\left(t_{17}=4.022, p<.001\right)$, and between task and recovery $\left(t_{17}=6.669, p<.0001\right)$.

As to the systolic blood pressure, Figure 2 shows average values of groups in each phase.

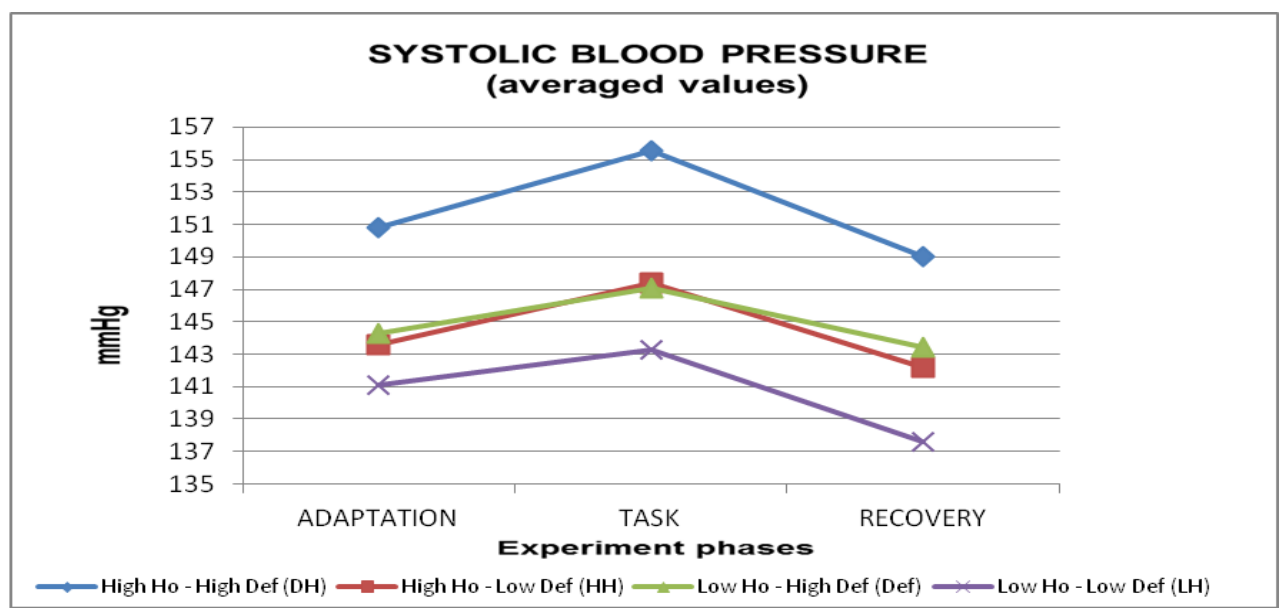

Figure 2. Systolic blood pressure averaged values obtained by the four groups in the three phases of the experiment.

ANOVA showed significant differences in the variable group $\left(F_{3,106}=2.97, p<.035\right)$ and in the variable phase $\left(F_{2,212}=62.10, p<.0001\right)$. A univariate analysis specific to each phase was conducted. Significant differences were noted in the task $\left(F_{3,106}=3.13, p<.029\right)$ and recovery $\left(F_{3,106}=3.40, p<.020\right)$ phases. The post hoc Scheffé test allowed us to find that the groups involved were $\mathrm{DH}$ and $\mathrm{LH}$ : task $($ dif $=12.24, p<.044)$, recovery $($ dif $=11.43, p<.024)$.
The intra-specific analyses, $t$-test, reveals significant differences in the four groups during the different phases. In the $\mathrm{DH}$ group, between adaptation and task $\left(t_{20}=-4.169\right.$; $p$ $<.0001)$, and between task and recovery $\left(t_{20}=5.905 ; p<\right.$ $.0001)$. In the $\mathrm{HH}$ group, between adaptation and task $\left(t_{35}=\right.$ -6.278; $p<.0001)$, and between task and recovery $\left(t_{35}=\right.$ 6.623; $p<.0001)$. In the Def group, between adaptation and task $\left(t_{34}=-4.476 ; p<.0001\right)$, and between task and recovery 
$\left(t_{41}=4.356 ; p<.0001\right)$. In the LH group, between adaptation and recovery $\left(t_{17}=2.211 ; p<.041\right)$, and between task and recovery $\left(t_{17}=5.020 ; p<.0001\right)$.
As to the diastolic blood pressure, Figure 3 shows the averaged values for each phase of the four groups.

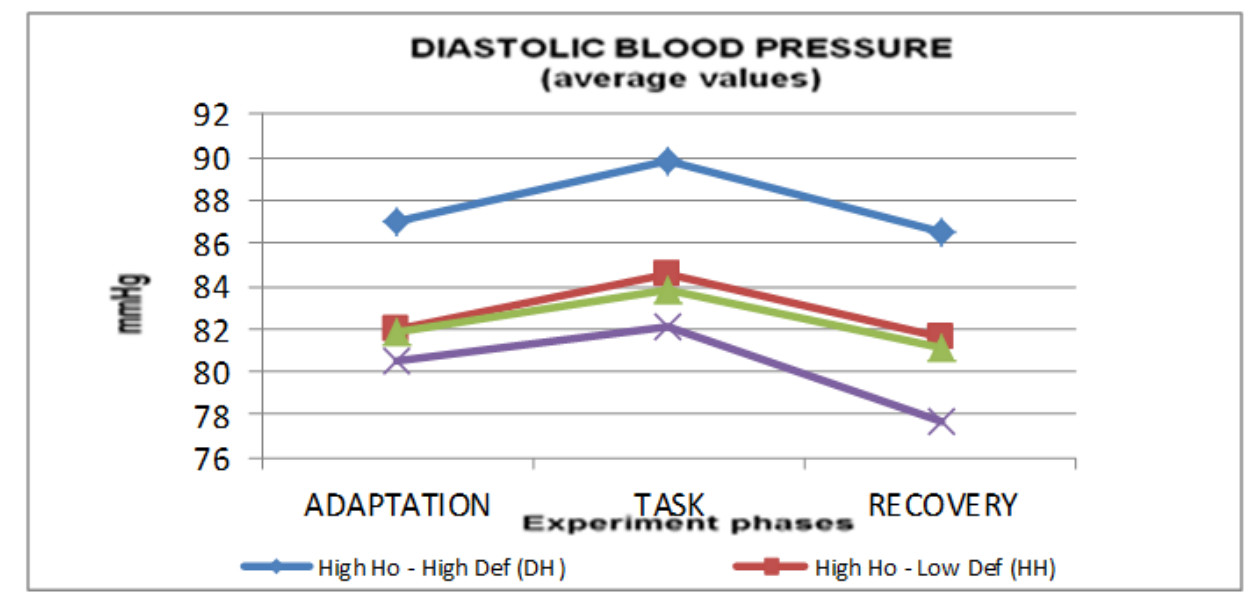

Figure 3. Diastolic blood pressure averaged values obtained by the four groups in the three phases of the experiment.

ANOVA allowed us to locate significant differences in the group $\left(F_{3,106}=2.75, p<.046\right)$ and phase $\left(F_{2,212}=40.84, p\right.$ $<.0001)$ variables. Univariate analysis showed significant differences in the recovery phase $\left(F_{3,106}=3.42, p<.020\right)$, and post hoc Scheffé test found that $\mathrm{DH}$ and $\mathrm{LH}$ groups were implicated (dif $=8.82, p<.024)$. The intra-specific analyses, t-test, also reveals significant differences in the four groups during the different phases. In the DH group, between adaptation and task $\left(t_{20}=-3.199 ; p<.005\right)$, and between task and recovery $\left(t_{20}=4.767 ; p<.0001\right)$. In the HH group, between adaptation and task $\left(t_{35}=-5.162 ; p<.0001\right)$, and between task and recovery $\left(t_{35}=4.408 ; p<.0001\right)$. In the Def group, between adaptation and task $\left(t_{34}=-3.721 ; p<.001\right)$, and between task and recovery $\left(t_{34}=4.796 ; p<.0001\right)$. In the LH group, between adaptation and recovery $\left(t_{17}=2.282\right.$; $p<.036)$, and between task and recovery $\left(t_{17}=4.791 ; p<\right.$ $.0001)$.

The second objective was to establish the functional significance of the overall profiles in the four groups formed by the hostility and defensiveness variables, considering the average, minute by minute, throughout phase. Analyzes were conducted on each of the three phases.

At the adaptation phase, an ANOVA with a mixed design 4 (groups DH, HH, Def and LH) x 10 (minutes), with repeated measures for the variable minute, was used.

With respect to heart rate, Figure 4 shows the averaged values for ten minutes in each group.

The conducted ANOVA did not find significant differences.

With respect to systolic blood pressure, Figure 5 shows the averaged values for ten minutes for each group.

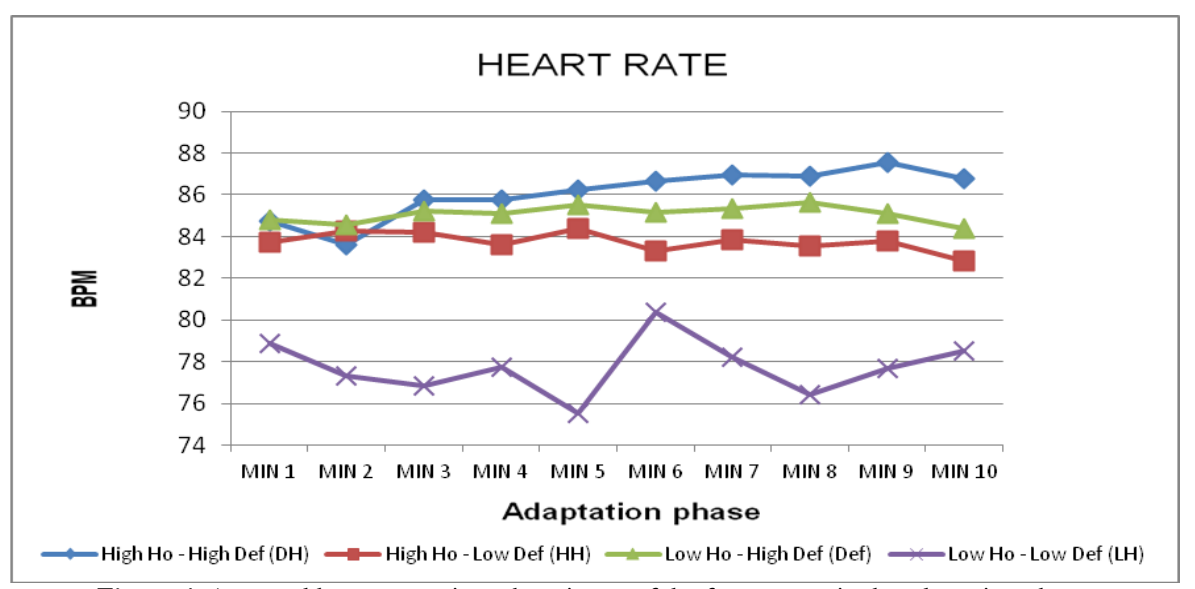

Figure 4. Averaged heart rate, minute by minute, of the four groups in the adaptation phase. 


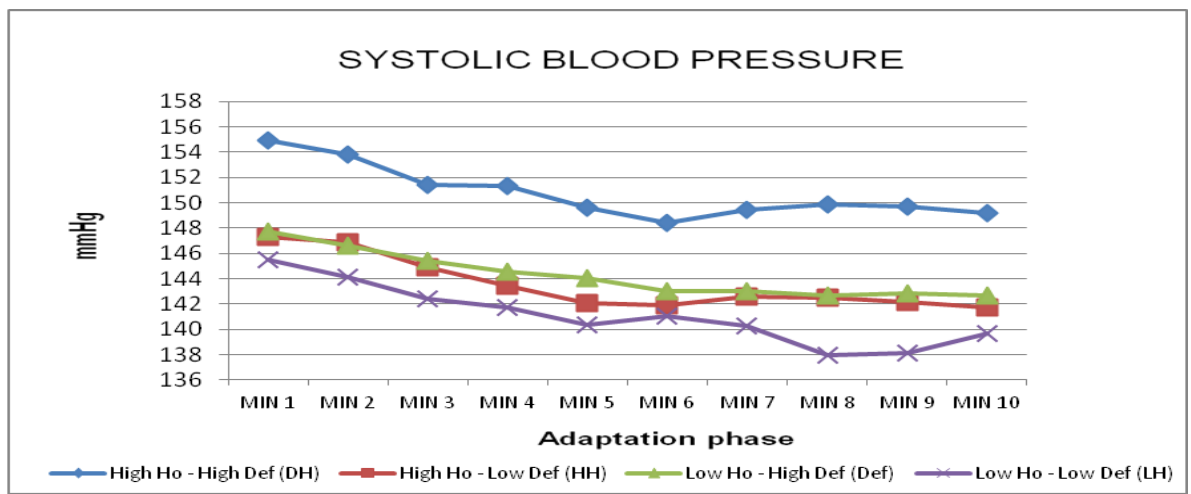

Figure 5. Averaged systolic blood pressure, minute by minute, of the four groups in the adaptation phase.

ANOVA show significant differences in minute variable $\left(F_{9,954}=38.27, p<.0001\right)$. Subsequent univariate analysis led to evidence that significant differences exist in the minutes 8 $\left(F_{3,106}=2.875, p<.04\right)$ and $9\left(F_{3,106}=2.965, p<.035\right)$. Scheffé post hoc test noted that DH and LH groups were con- cerned: minute 8 (dif $=11.93, p<.049)$, minute $9(\mathrm{dif}=$ $11.54, p<.046)$.

With respect to diastolic blood pressure, Figure 6 shows the averaged values for ten minutes for each group.

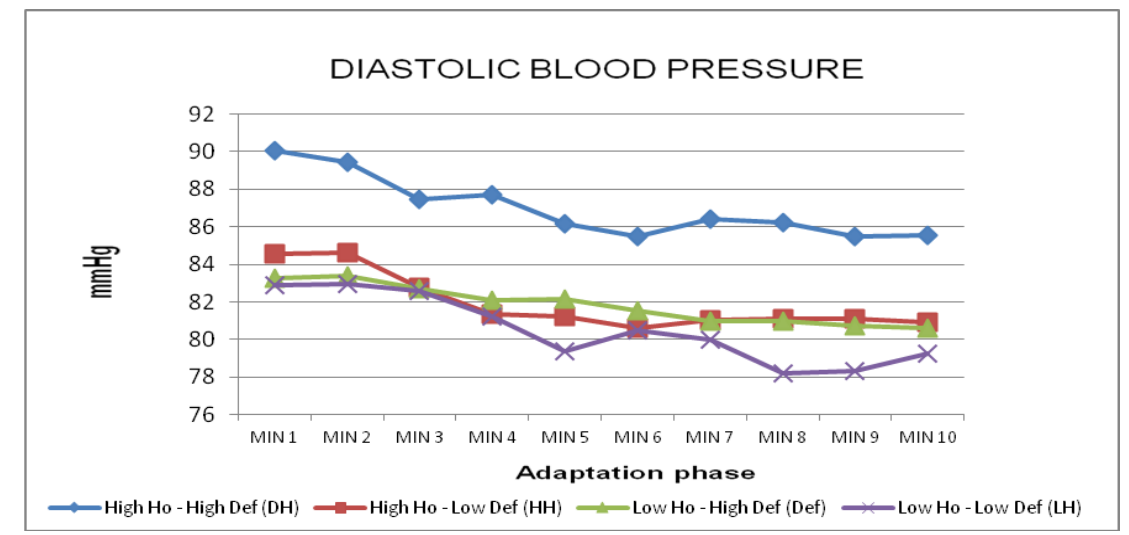

Figure 6. Averaged diastolic blood pressure, minute by minute, of the four groups in the adaptation phase

ANOVA showed significant differences in the variable minute $\left(F_{9,954}=23.102, p<.0001\right)$,

although no significant differences were located with subsequent univariate analysis.
At the task phase, an ANOVA with a mixed design 4 (groups DH, HH, Def and LH) x 20 (minutes), with repeated measures for the variable minute, was used.

With respect to heart rate, Figure 7 shows the averaged values for twenty minutes in each group.

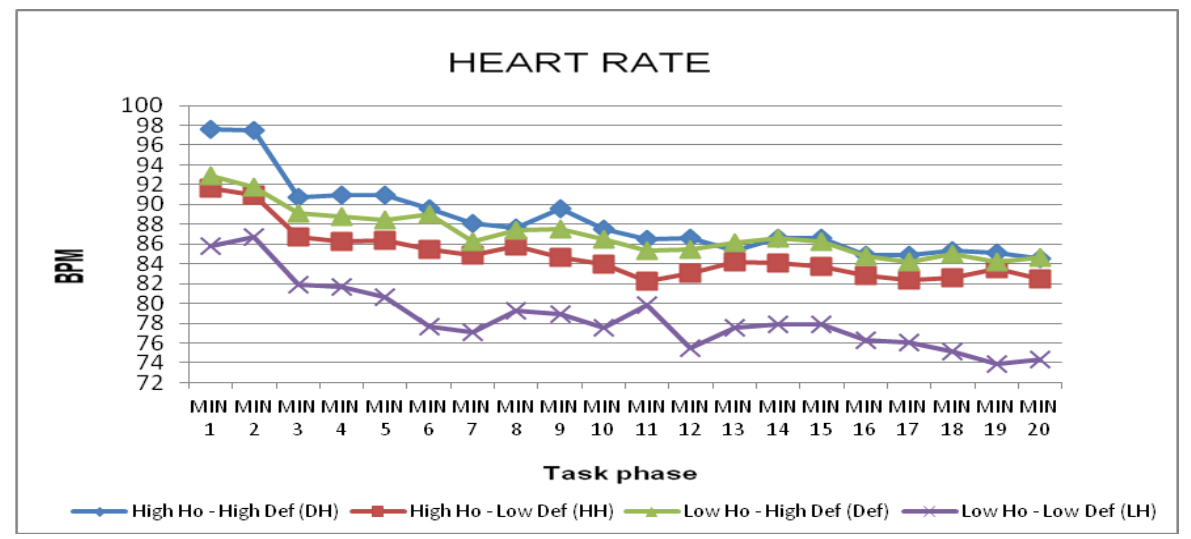

Figure 7. Averaged heart rate, minute by minute, of the four groups in the task phase 
ANOVA showed significant differences in the variable minute $\left(F 1_{9,2014}=33.33, p<.0001\right)$. Subsequent univariate analysis led to evidence that significant differences exist in the minutes 6, 19 and 20. Minute $6\left(F_{3,106}=3.304, p<.023\right)$; Scheffé post hoc shows differences between Def and LH groups $(\mathrm{dif}=11.36, p<.048)$. Minute $19\left(F_{3,106}=3.884, p<\right.$ .011); Scheffé post hoc shows differences between $\mathrm{DH}$ and
LH groups $($ dif $=11.22, p<.037)$. Minute $20\left(F_{3,106}=3.189, p\right.$ $<.027)$;

Scheffé post hoc shows differences between Def and LH groups (dif $=10.31, p<.044)$.

With respect to systolic blood pressure, Figure 8 shows the averaged values for twenty minutes in each group.

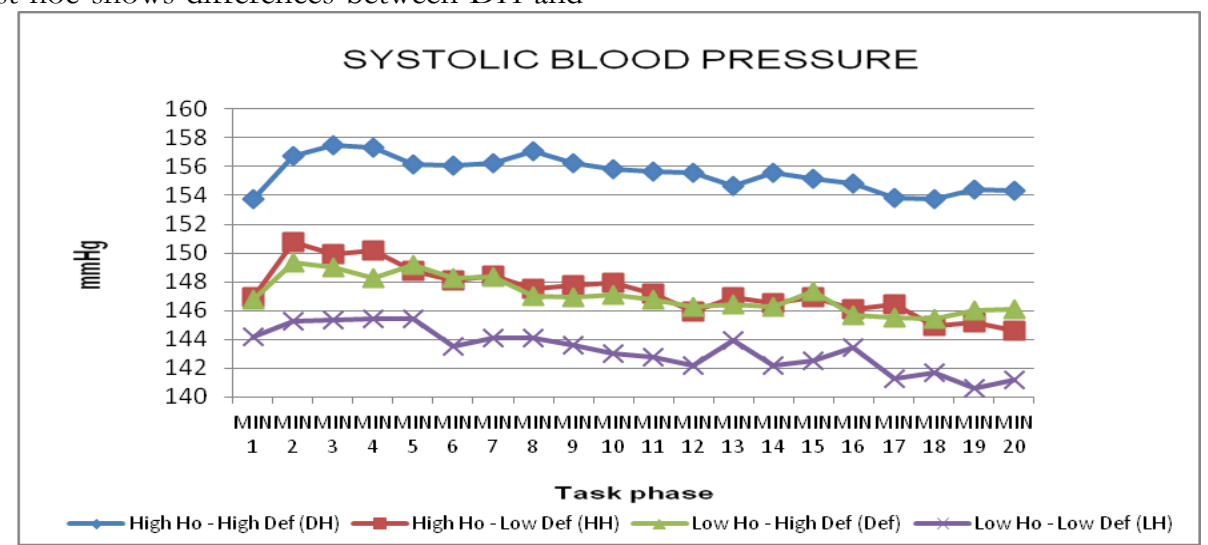

Figure 8. Averaged systolic blood pressure, minute by minute, of the four groups in the task phase

ANOVA showed significant differences in the group $\left(F_{3,106}=3.133, p<.029\right)$ and minute $\left(F_{19,2014}=11.345, p<\right.$ .011) variables. Subsequent univariate analysis showed significant differences in the minutes $8,11,12,14,15,16,17,18$, 19 y 20. Scheffé post hoc test showed that, in all cases, the groups involved were $\mathrm{DH}$ and $\mathrm{LH}$ : minute $8\left(F_{3,106}=3.464, p\right.$ $<.019)$, $($ dif $=12.96, p<.042)$; minute $11\left(F_{3,106}=3.084, p<\right.$ $.031),($ dif $=12.83, p<.046) ;$ minute $12\left(F_{3,106}=3.641, p<\right.$ $.015),($ dif $=13.41, p<.028)$; minute $14\left(F_{3,106}=3.689, p<\right.$
$.014),($ dif $=13.42, p<.024) ;$ minute $15\left(F_{3,106}=3.034, p<\right.$ $.032),($ dif $=12.62, p<.043)$; minute $16\left(F_{3,106}=2.998, p<\right.$ $.034),($ dif $=11.42, p<.047)$; minute $17\left(F_{3,106}=3.232, p<\right.$ $.025),($ dif $=12.50, p<.034) ;$ minute $18\left(F_{3,106}=3.141, p<\right.$ $.028),($ dif $=12.09, p<.049)$; minute $19\left(F_{3,106}=4.033, p<\right.$ $.009)$, $($ dif $=13.86, p<.014)$; minute $20\left(F_{3,106}=4.007, p<\right.$ $.010),($ dif $=13.10, p<.019)$.

With respect to diastolic blood pressure, Figure 9 shows the averaged values for twenty minutes in each group.

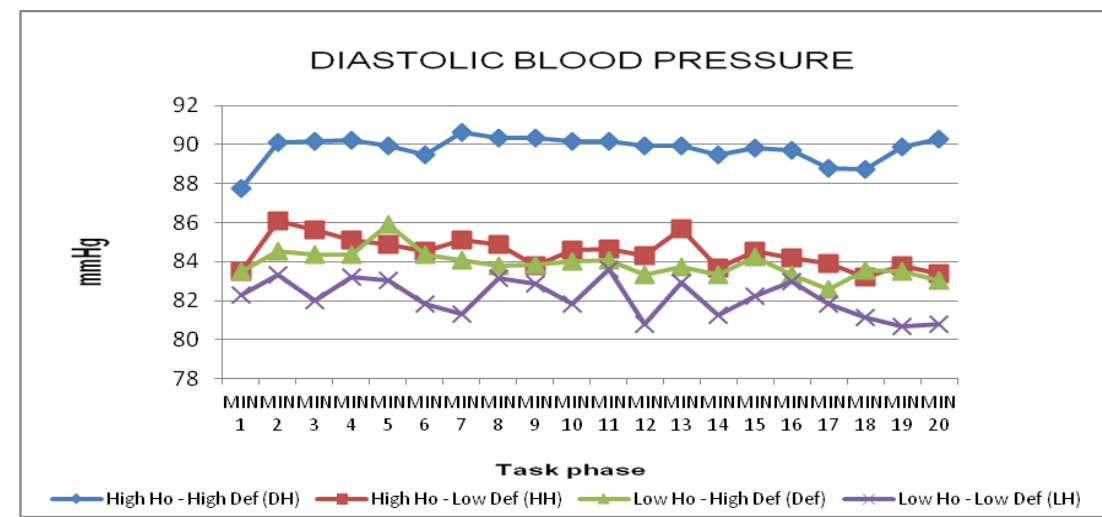

Figure 9. Averaged diastolic blood pressure, minute by minute, of the four groups in the task phase

ANOVA showed significant differences in the variable minute $\left(F_{19,2014}=2.556, p<.0001\right)$, and subsequent univariate analysis noted differences in minutes 7,19 and 20. Also in this case Scheffé post hoc test showed that the involved groups were $\mathrm{DH}$ and $\mathrm{LH}$ : minute $7\left(F_{3,106}=3.136, p<.029\right)$, (dif $=9.31, p<.042)$; minute $19\left(F_{3,106}=3.286, p<.024\right)$, (dif $=9.20, p<.037)$; minute $20\left(F_{3,106}=4.073, p<.009\right)$, $($ dif $=$ $9.52, p<.021)$.
At the recovery phase, an ANOVA with a mixed design 4 (groups DH, HH, Def and LH) x 10 (minutes), with repeated measures for the variable minute, was used. With respect to heart rate, Figure 10 shows the averaged values for ten minutes in each group.

ANOVA showed no significant differences.

With respect to systolic blood pressure, Figure 11 shows the averaged values for ten minutes in each group. 


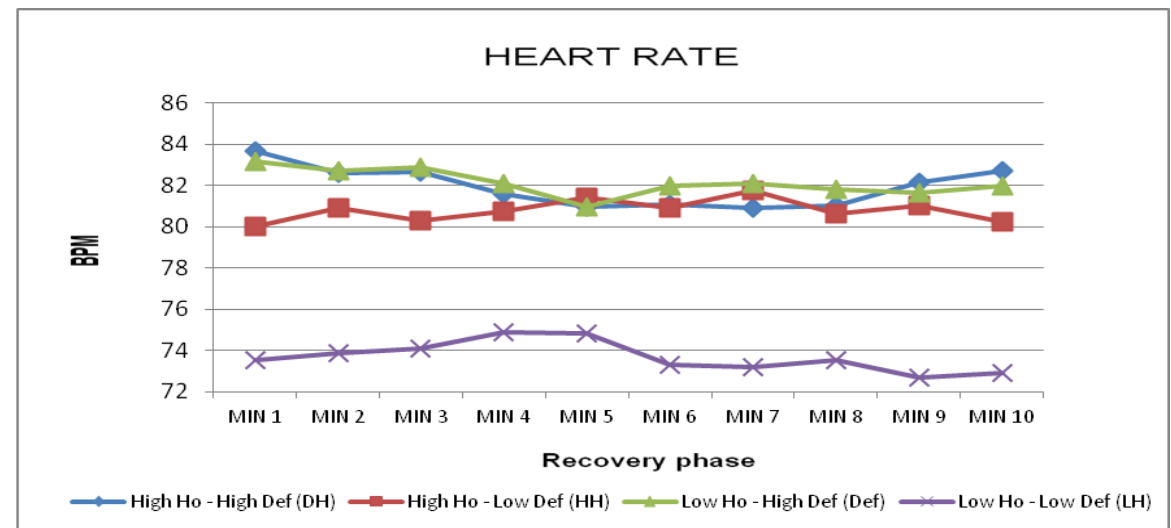

Figure 10. Averaged heart rate, minute by minute, of the four groups in the recovery phase

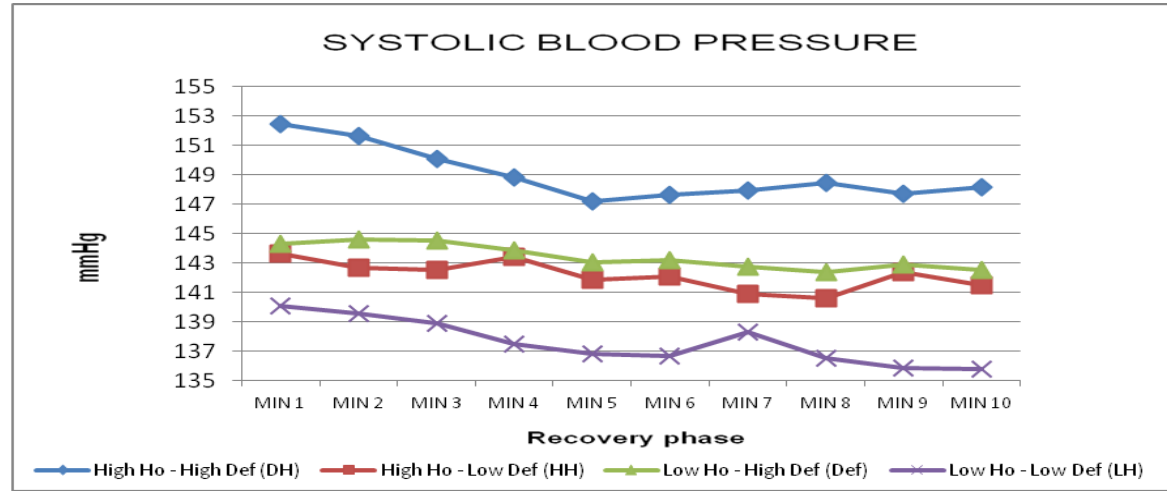

Figure 11. Averaged systolic blood pressure, minute by minute, of the four groups in the recovery phase

ANOVA showed significant differences in the group $\left(F_{3,106}=8.405, p<.020\right)$ and minute $\left(F_{9,954}=13.334, p<\right.$ $.0001)$ variables. Univariate analysis noted differences in every minute, and Scheffé post hoc test highlighted that involved groups were $\mathrm{DH}$ and $\mathrm{LH}$ : minute $1\left(F_{3,106}=3.637, p<\right.$ $.015),($ dif $=12.41, p<.026) ;$ minute $2\left(F_{3,106}=3.887, p<\right.$ $.011),($ dif $=12.03, p<.022)$; minute $3\left(F_{3,106}=3.200, p<\right.$ $.026),($ dif $=11.24, p<.038) ;$ minute $4\left(F_{3,106}=2.828, p<\right.$ $.042),($ dif $=11.39, p<.043)$; minute $5\left(\mathrm{~F}_{3,106}=2.785, p<\right.$
$.044),($ dif $=10.36, p<.048) ;$ minute $6\left(F_{3,106}=2.998, p<\right.$ $.034),($ dif $=10.97, p<.037)$; minute $7\left(F_{3,106}=2.795, p<\right.$ $.043),($ dif $=10.72, p<.045)$; minute $8\left(F_{3,106}=3.858, p<\right.$ $.012),($ dif $=11.98, p<.017)$; minute $9\left(F_{3,106}=3.532, p<\right.$ $.017),($ dif $=11.90, p<.018)$; minute $10\left(F_{3,106}=3.468, p<\right.$ $.019),($ dif $=12.37, p<.020)$.

With respect to diastolic blood pressure, Figure 12 shows the averaged values for ten minutes in each group.

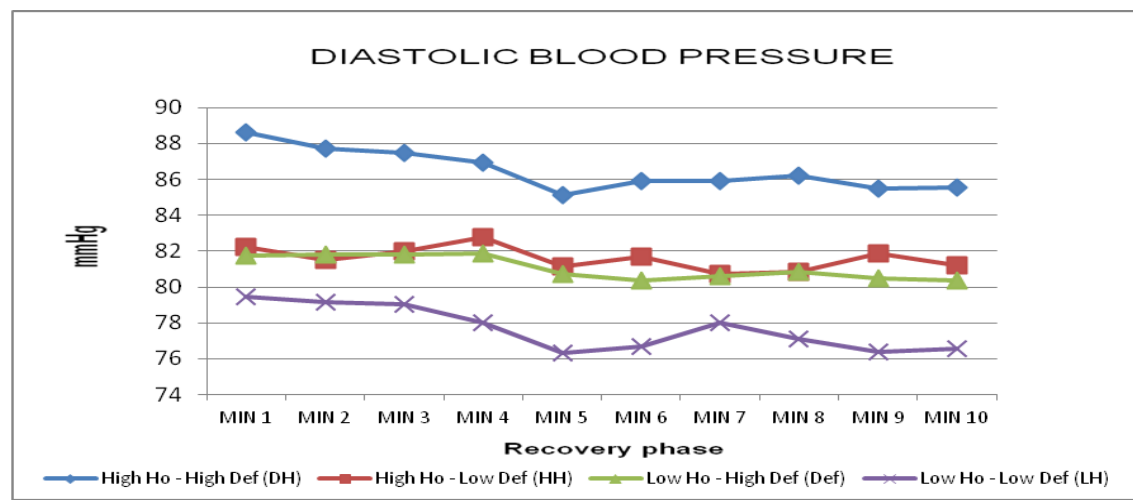

Figure 12. Averaged diastolic blood pressure, minute by minute, of the four groups in the recovery phase 
ANOVA showed significant differences in the group $\left(F_{3,106}=3.426, p<.020\right)$ and minute $\left(F_{9,954}=7.331, p<.0001\right)$ variables. Subsequent univariate analysis showed differences in the minutes $1,2,3,5,6,8,9$ y 10 . As noted Scheffé post hoc test, in all the cases, groups involved were DH and LH: minute $1\left(F_{3,106}=3.652, p<.015\right)$, (dif $\left.=9.14, p<.030\right)$; minute $2\left(F_{3,106}=3.405, p<.020\right)$, $($ dif $=8.56, p<.037)$; minute $3\left(F_{3,106}=3.131, p<.029\right),($ dif $=8.45, p<.041)$; minute 5 $\left(F_{3,106}=2.876, p<.040\right),($ dif $=8.80, p<.040)$; minute 6 $\left(F_{3,106}=3.354, p<.022\right),(\operatorname{dif}=9.27, p<.026)$; minute 8 $\left(F_{3,106}=3.485, p<.018\right),($ dif $=9.10, p<.022) ;$ minute 9 $\left(F_{3,106}=3.640, p<.015\right),($ dif $=9.11, p<.018)$; minute 10 $\left(F_{3,106}=2.982, p<.035\right),($ dif $=8.97, p<.038)$.

\section{Discussion}

In general, it may be stated that the results indicate the expected direction, which enables the assertion that the proposed hypotheses were fulfilled. Also, when there are no previous studies (minute by minute evolution within each phase), our results show interesting aspects related to the proposal made by Kelsey (1993) regarding the profiles functionality or dysfunctionality.

With respect to first objective, that is: to establish the functional significance of the overall profiles in the four groups formed by the hostility and defensiveness variables, considering each of the three cardiovascular variables along the three phases of the experiment, our results confirmed the proposed hypothesis, as defensive hostile individuals have a profile characterized by a higher activation in the task phase and a slower recovery.

Our results are consistent with those obtained in previous studies, that is, that defensive hostile people obtain the highest values in the task phase (Brosschot, Gerin, \& Thayer, 2006; Helmers, \& Krantz, 1996; Jorgensen, \& Thibodeau, 2006; Larson, \& Langer, 1997; Shapiro, Goldstein, \& Jamner, 1995; Vella, \& Friedman, 2007). Moreover, we have found that this group of individuals takes longer to recover after a stress situation, that is, they score the highest values encountered during the recovery phase. These results are similar to those found in previous studies (Anderson, Linden, \& Habra, 2005; Guerrero, \& Palmero, 2010; Palmero, \& Guerrero, 2012).

The profile characterized by high activation and a slow recovery could be related to the increased risk of cardiovascular dysfunctions. The theoretical foundation of this increased risk in individuals hostile defensive derived from the fact that catecholamines, adrenaline and noradrenaline, which are released during stressful situations to enable the individual to confront this situation with guarantees, may become harmful. So, when that level is excessive (which occurs during the task, when the individual produces the coping response), or long stay in the blood (which occurs during the recovery phase, when the individual needs more time to recover basal activation levels), the greater the risk of adverse impacts.
Moreover, when we analyzed the three cardiovascular variables studied, the systolic and diastolic pressures seem more powerful than the heart rate to indicate the risk of dysfunction. Our results agree with those of previous work (Helmers, and Krantz, 1996; Jorgensen, Abdul-Karim, Kahan, \& Frankowsi, 1995; Mente, \& Helmers, 1999), suggesting that the systolic index better reflects the high activation in hostile defensive individuals. Probably, heart rate is a more stable parameter, and does not allow the detection of small changes that may be occurring when the individual tries to cope with a stressful situation. The fact that the defensive hostile group presents higher scores for these values once again coincides with the preliminary studies carried out in the laboratory context, confirms our assumptions, and leads us to suggest that defensive hostility rather than hostility alone better predicts the cardiovascular function in situations of stress. Defensive hostility identifies a dimension of personality that, ultimately, would be a better predictor of the cardiovascular response in particular and of cardiovascular disease in general. It would be more fitting than hostility alone to explain and understand cardiovascular functioning in stressful situations.

Our results totally coincide with those of the study by the Shapiro, Goldstein, and Jamner (1995), which shows that those individuals with high scores in hostility and high scores in defensiveness are those who reflect the highest values in activation and cardiovascular response, but only when faced with the demands of a challenging task. For this reason, and as we have pointed out, it seems appropriate to use a real situation of stress as an experimental task because this specific environment is the best scenario to see the psychophysiological response style that characterizes the individuals being studied.

Overall, results of the first objective are consistent with previous studies proposals regarding defensive hostility as a construct of interest for the study of risk of cardiovascular dysfunction. Hostile defensive individuals show the Kelsey (1993) proposed dysfunctional profile, characterized by high activation during task phase and the slow habituation in the recovery phase.

With respect to second objective, that is, to establish the functional significance of cardiovascular profiles in each of the four groups when considering the evolution of the studied parameters within each phase, our results confirmed the proposed hypothesis, as during the adaptation and task phase, the hostile defensive individuals' profile shows maintenance or sensitization, and during the recovery phase, the hostile defensive individuals' profile shows a slow recovery. The absence of previous work with these same characteristics prevents us from comparing our data. Therefore, we will try to discuss the results, making suggestions for future research.

Regarding the adaptation phase, concerning HR, it was observed that the DH group presented a progressive sensitization profile during the evolution throughout the phase. Indeed, not only this group showed no habituation to the ex- 
perimental situation, but its HR increased gradually as the task phase approached.

Concerning SBP and its evolution throughout the adaptation phase, especially from the halfway point, it is noted that the $\mathrm{DH}, \mathrm{HH}$ and Def groups presented a very slow decrease and showed a maintenance profile. Otherwise, the LH group presents a habituation trend, although in the last minute increases the HR value regarding the previous minutes values. Therefore, the hypothesis was fulfilled in terms of a constant profile that the DH group presented, though the profile this group displayed was very similar to that presented by $\mathrm{HH}$ and Def groups. Even so, a fact to be mentioned is the highest mean value of $\mathrm{DH}$ group throughout this phase in relation to the other three groups.

Concerning DBP, by considering the profiles in general, it can be seen that all groups displayed a habituation profile during its evolution throughout the adaptation phase. However, looking more carefully in the second half of this phase, it is noted that the HH, DH and Def groups presented a slower habituation; it rather reflects almost a constant profile. Whereas the LH group presented a clear habituation profile in the second half of the adaptation phase, albeit there is a small increase in the final minute in relation to the previous minutes. Even so, once again the $\mathrm{DH}$ group showed the highest values through all this phase.

Interestingly, the adaptation phase could reflect an adjustment scenario. This scenario might be a reflection of the anticipatory anxiety phenomenon (Butler, \& Mathews, 1987). A situation in which the individual knows he will face a stressful situation shortly, but not knows the type of stimuli that will appear. In these situations, the defensive hostility construct is a good criterion to predict cardiovascular psychophysiological functioning. Our results lead us to suggest that, in anticipatory anxiety situations, hostility and defensiveness, alone or combined, trigger a greater cardiovascular response. Specifically, DH group feel more affected by uncertainty, and cognitive functioning in this group appears to be better reflected by heart rate.

The fact that the DH group showed higher values, and the lowest the LH group, in the three studied cardiovascular parameters allows us to suggest that defensive hostility Individuals are those who may have an increased risk of cardiovascular dysfunction.

Furthermore, the fact that the LH group displayed a profile of habituation in both blood pressure parameters allows us to make two suggestions: On the one hand, hostility and defensiveness, alone or combined, produce a higher response in the two blood pressures, as the LH group, which is characterized by low scores on hostility and defensiveness, is the one with the fastest habituation. Furthermore, secondly, this feature of the LH group habituation is more readily appreciated through systolic blood pressure and diastolic blood pressure. However, the lack of previous work leads us to propose the replication of these studies to confirm our suggestion. Our initial data could help better understand the cardiovascular functioning of individuals at risk of dysfunction.

Regarding the task phase, concerning HR, a process of habituation occurs in all groups. The fact that the most obvious habituation profile is shown by the $\mathrm{LH}$ group again allows us to suggest that hostility and defensiveness variables play a role in cardiovascular response mechanisms. That is, the only group which shows a clear habituation response is the LH. The other three groups, which began with a gradual habituation process, displayed a significant slowing-down of their habituation profile toward the halfway stage of the phase. Despite the fact they presented a habituation profile, it is evident that this habituation was so slow that it might suggest a maintenance profile. The fact that the LH group, compared with the DH group, showed lower levels of HR and a more adaptive habituation profile is consistent with the idea of the important role that hostility and defensiveness play in the cardiovascular functioning.

Concerning SBP, the same as the heart rate is observed, but in this case the profiles are clearer. In all groups there is a habituation profile. However, the DH group profile shows a remarkable slowness in the process. The important difference from the LH group also allows us to argue that the variables of hostility and defensiveness are appropriate to detect the potential risk of cardiovascular dysfunction. DH group habituation shows a profile that looks more like a maintenance profile, reflecting the continued activation in stress. Then, we can propose that high scores on hostility and defensiveness are associated with increased risk of cardiovascular dysfunction, and the SBP is an appropriate parameter to detect this risk. In terms of evolution throughout the task phase, all four groups showed a habituation profile. However, if we look at the initial and final values of each group, it is noticed that the $\mathrm{DH}$ group presented very similar values at both times, indicating very slow habituation or maintenance. Consequently, it may be stated that our hypothesis was confirmed: although hostility and defensiveness are variables that produce high cardiovascular activation, the combination of both, the defensive hostility, produces the greatest response.

Concerning DBP evolution throughout the task phase, albeit very slowly, a habituation profile was observed in three groups, HH, Def and LH. And the other hand, as expected, the DH group showed a maintenance -even sensitizationprofile at the last minutes. It might be suggested that DBP presented a more labile index than SBP, a circumstance which may be established observing the variability that the profiles of all groups showed. With BPD, similar to what we observed with SBP occurs. That is, the hostility and defensiveness variables have a significant influence on cardiovascular function in actual stressful situations. The biggest impact is when both variables are combined, allowing us to propose that defensive hostility is a better predictor of cardiovascular function in stressful situations than hostility alone. As SBP, DBP seems an appropriate parameter to detect increased risk of $\mathrm{DH}$ group. 
We can establish a differential relevance between different cardiovascular parameters. On the one hand, we might suggest that blood pressure is the best parameter to differentiate between groups under stress. Applying a different psychophysiological methodology (detailed analysis of the evolution of cardiovascular parameters along the phase), our results agree generically with those of other studies (Larson, \& Langer, 1997; Mente, \& Helmers, 1999), in which it is proposed that blood pressure is the best predictor of group differences when using variables of hostility and defensiveness. On the other hand, we also suggest that heart rate seems the most appropriate parameter to detect differences between groups in situations of stress prior to coping, that is: in anticipatory anxiety situations.

With respect recovery phase, Concerning HR, it is generally noted that all groups displayed a very slow recovery, which reflect a rather constant profile. However the more detailed analysis carried out in this experiment revealed that, as from the second half of the phase, after five minutes of recovery, the intermediate groups ( $\mathrm{HH}$ and Def) already displayed stable HR values, while the same values of the $\mathrm{DH}$ group actually increased in the last few minutes, which not only indicates slow recovery, but also slight sensitization. Another interesting fact of this scenario should be added; during this same period, that is, as from the second half of the phase, the LH group conversely presented a habituation profile that corresponded to recovery, which was also more rapid than in the other groups. In the same vein, we should point out that although this finding is consistent with our hypothesis, we are unable to corroborate or compare it with other data given the lack of studies that have analysed these developments in detail within each phase in question. Importantly, scores on hostility and defensiveness appear to be associated with the values of heart rate, which tells us the importance of hostility and defensiveness as appropriate parameters to detect the risk of cardiovascular dysfunction. This increased association is found when hostility and defensiveness are combined.

Thus, the groups in which a high hostility $(\mathrm{HH})$ or defensiveness (def) score exist show higher values in heart rate than group with low hostility and low defensiveness (LH) scores. When both variables are combined $(\mathrm{DH})$, the highest values were observed in heart rate. For heart rate, it is clear that defensive hostility has greater predictability of cardiovascular function that hostility alone. In future works, it would be interesting to extend the duration of this phase to check if a clearer profile of habituation is done.

Concerning SBP, although an overall habituation profile was seen in all four groups, we also found interesting data by studying psychophysiological measures evolution minute by minute. Thus, the DH group presented a maintenance profile, and even slight sensitization, particularly as from the middle of the phase, which is most interesting because the participants had already experienced a five-minute recovery. The other high hostility group, $\mathrm{HH}$, showed a similar profile with even greater sensitization during the two last minutes, comparing with the previous minutes of this second half of the phase.

Again, these facts lead us to suggest the desirability of extending temporarily the recovery phase to establish a more appropriate profile for each group. That is, to see if they are indeed producing a profile of habituation, and what is more important: what is the time it takes each group to recover without stress situations baseline levels.

Furthermore, also in the case of blood pressure, it is important to emphasize the influence of hostility and defensiveness, alone or in combination, to assess the risk of cardiovascular dysfunction, a fact which is confirmed with $\mathrm{LH}$ and $\mathrm{DH}$ group profiles. It is important to stress this point because the only account of hostility as a criterion to predict the possible occurrence of cardiovascular dysfunction could have been biasing the systematically obtained results. This finding seems to be of remarkable importance as it indicates that DH is a better predictor criterion than hostility alone when it comes to localizing the potential risk of cardiovascular dysfunction. This assertion is based on the main effect of the defensiveness variable. Furthermore, it is feasible to suggest that the SBP variable is more conclusive than HR to portray these differences.

Concerning DBP, the most interesting data were observed, especially in the second half of this phase. Thus while observing the overall profile, it can be seen that all groups presented a habituation profile. However, it is middle through this phase when it was observed that all four groups reflected a maintenance profile. Moreover, it was noticed that the profile of the DH group reflected a slight and slower recovery, which is a result of a slight increase in the DBP values in the second half of this phase. Once more, these data are consistent with those described for the general profiles in the first objective of this study: alone or in combination, produce a greater activation, which in this case is reflected by the slow recovery, and DH group shows the slower recovery pattern. Besides, as in other cardiovascular parameters, we believe that the temporary extension of the recovery phase would allow us to establish more clearly the profiles of the four groups. It seems that there is no clear trend of habituation.

We believe that inclusion of the recovery phase in this type of experimental laboratory research must be stressed and it constitutes a basic and essential element in the detection of possible risks of future dysfunctions. From a neuroendocrinological viewpoint, it is important to consider the consequences caused by the situation, since the more time the organism needs to recover the BL levels, the greater the exposure to the effects of the substances released (catecholamines and cortisol).

\section{Conclusions}

Overall, our results confirm the hypotheses, as the DH group is characterized by a profile which produces mainte- 
nance -even sensitization- in task phase, and slow habituation in the recovery phase.

The recovery phase is a critical variable, because it allows us to know the pace of adjustment of the body after a stressful situation. Moreover, as pointed out recently by Shcheslavskaya et al. (2010), the pattern of recovery after a cognitive challenge was preserved with age. This allows us to argue, as suggested in previous works (Palmero, Breva, \& Landeta, 2002; Palmero, \& Guerrero, 2012), that the recovery phase is a good indicator of possible cardiovascular disorders, because their relative constancy over time varying announces the risk of the disease.

In short, we may state that the data obtained in this study, by means of the detailed analysis of the profile's functionality in each phase, expand the information and findings obtained to date. The studies conducted in the basic experimental psychophysiology field have systematically analysed the response profiles when the average values of each phase are considered. This fact may have masked a very different physiological function either among the various profiles considered or either different individuals with similar values in a particular phase. One solution to delimit values from which a specific average is established consists in directly discovering all those values that lead to this average. This is precisely what can be seen examining and analysing the index evolution by each phase, in each group at each given time.

Defensive hostility is a good predictor of cardiovascular function and the possible occurrence of cardiovascular disorders. Our results agree with those of Brosschot et al. (2006), while the combination of high hostility and defensiveness is related to the increase in scores in systolic and diastolic pressure in stressful situations. Furthermore, they are also associated with longer duration of the recovery process. Therefore, as we have noted throughout this work, the recovery phase also becomes an appropriate parameter to detect cardiovascular disease risk, and the study of the cardiovascular parameters evolution throughout each phase can help better understand this potential risk.

Ultimately, we emphasize some aspects that we consider of interest.

Firstly, the relationship between defensive hostility and the various cardiovascular indexes recorded (HR, SBP and DBP), in the different phases of the study (adaptation, task and recovery phase), has been demonstrated. Separately, high hostility scores or high defensiveness scores produce an increment in cardiovascular activation. The combination of both variables, ie defensive hostility, is the one that produces the highest levels of activation. Such activation is showing all during the task, with a greater response, and during the recovery phase, with a slower habituation. The DH group is showing these characteristics. That is: defensive hostility has proved to be a more appropriate criterion than hostility alone when determining the possible risk of cardiovascular dysfunction, concretely because these individuals have an exaggerated cardiovascular functioning, especially in real stressful situations. This fact has already been previously suggested in other studies (Palmero et al., 2007).

Even as indicated Hausteiner, Klupsch, Emeny, Baumert and Ladwig (2010), we think defensive hostility could be considered as an independent prognostic risk factor for cardiovascular disease.

Secondly, thanks to the detailed analysis of each phase in the experiment, it was obtained further valuable information on the evolution and the differences in the cardiovascular function of each group at each given time, and considering several cardiovascular parameters. Blood pressure seems the best parameter for assessing the cardiovascular response to stressful situations. Heart rate seems the best parameter to assess the cardiovascular functioning in anticipatory anxiety situations.

Thirdly, in relation to the phase duration, we believe it is also particularly relevant to propose experimental tasks that are long enough to safely establish real cardiovascular functioning in order to observe how adaptation to the stressful situation comes about, or not. Also believe that the recovery phase has to be long enough to detect the true profile of habituation of the subjects after performing the stress task. We suggest increasing the task and recovery duration in future works.

In sum, this research has attempted to examine an important aspect within the theoretical framework on $\mathrm{DH}$ as a possible psychosocial cardiovascular risk factor, applying a new psychophysiological methodology to discover the possible connection between psychological factors and physiological functioning. Are results that can help better understand the risk of cardiovascular dysfunction defensive hostile individuals.

There are some limitations that should be considered in further research. One of the limitations of this study is that the sample has comprised only women, youth and university students. As a future research direction, the probable variability among females as compared to males necessitates concentrated research in the cardiovascular functioning area. Another aspect of interest could be the consideration of percentiles or z scores as cutoffs to form groups, to find out if there are more powerful results. Another concern relates to the possibility of taking self-report measures of perceived stress in participants, it could have an effect on cardiovascular functioning. Although we assume that an exam test situation is a real stress situation, perceived stress information would provide useful data.

Acknowledgments.- This investigation was supported by grant P1-1B2003-24, from Fundació Caixa Castelló - Bancaixa 


\section{References}

Anderson J. C., Linden, W., \& Habra, M. E. (2005). The importance of examining blood pressure reactivity and recovery in anger provocation research. International Journal of Psychophysiology, 57, 159-163.

Avila, A., \& Tomé, M. C. (1989). Evaluación de la deseabilidad social y correlatos defensivos emocionales. Adaptación castellana de la Escala de Crowne y Marlowe. In A. Echevarría \& D. Páez (Eds.), Emociones: perspectivas psicosociales (pp. 505-513). Madrid: Fundamentos

Barefoot, J. C., Dodge, K., Peterson, B., Dahlstrom, W. G., \& Williams, R. B. (1989). The Cook-Medley Hostility Scales: Item content and ability to predict survival. Psychosomatic Medicine, 51, 46-57.

Boyle, S. H., Williams, R. B., Mark, D. B., Brummett, B. H., Siegler, I. C., Helms, M. J., \& Barefoot, J. C. (2004). Hostility as a predictor of survival in patients with coronary artery disease. Psychosomatic Medicine, 66, 629-632.

Brosschot, J. F., Gerin, W., \& Thayer, J. F. (2006). The perseverative cognition hypothesis: A review of worry, prolonged stress-related physiological activation, and health. Journal of Psychosomatic Research, 60, 113-124.

Brydon, L., Strike, P. C., Bhattacharyya, M. R., Whitehead, D. L., McEwan, J., Zachary, I., \& Steptoe, A. (2010). Hostility and physiological responses to laboratory stress in acute coronary syndrome patients. Journal of Psychosomatic Research, 68(2), 109-116.

Butler, G., \& Mathews, A. (1987). Anticipatory anxiety and risk perception. Cognitive Therapy and Research, 11(5), 551-565.

Cannon, W. B. (1932). The wisdom of the body. New York: Norton.

Cedrus Corporation (2008). SuperLab Pro: Experimental Laboratory Software (Version 4.0.7b) [software de ordenador]. San Pedro, CA.

Chida, Y., \& Steptoe, A. (2009). The Association of Anger and Hostility with Future Coronary Heart Disease. A Meta-Analytic Review of Prospective Evidence. Journal of the American College of Cardiology, 53(11), 936-946.

Christensen, A., \& Smith, T. (1993). Cynical hostility and cardiovascular reactivity during self-disclosure. Psychosomatic Medicine, 55, 193-202.

Cook, W. W., \& Medley, D. M. (1954). Proposed hostility and pharisaic-virtue scales for the MMPI. Journal of Applied Psychology, 38, 414-418.

Crowne, D. P., \& Marlowe, D. (1960). A New Scale of Social Desirability Independent of Psychopathology. Journal of Consulting Psychology, 24, 349-354.

Denollet, J., Gidron, Y., Vrints, C. J., \& Conraads, V. M. (2010). Anger, suppressed anger, and risk of adverse events in patients with coronary artery disease. American Journal of Cardiology, 105, 1555-1560.

Everson-Rose, S. A., \& Lewis, T. T. (2005). Psychosocial factors and cardiovascular diseases. Annual Review of Public Health, 26, 469-500.

Guerrero, C., \& Palmero, F. (2010). Impact of defensive hostility in cardiovascular disease. Behavioral Medicine, 36(3), 77-84.

Hausteiner, C., Klupsch, D., Emeny, R., Baumert, J., \& Ladwig, K. H. (2010). Clustering of Negative Affectivity and Social Inhibition in the Community: Prevalence of Type D Personality as a Cardiovascular Risk Marker. Psychosomatic Medicine, 72(2), 163-171.

Helmers, K. F., Krantz, D. S., Merz, C. N. B., Klein, J., Kop, W. J., Gottdiener, J. S., \& Rozanzki, A. (1995). Defensive hostility: Relationship to multiple markers of cardiac ischemia in patients with coronary disease. Health Psychology, 14, 202-209.

Helmers, K. F., \& Krantz, D. S. (1996). Defensive hostility, gender and cardiovascular levels and responses to stress. Annals of Behavioral Medicine, 18, 246254.

Hernandez, D. H., Larkin, K. T., \& Whited, M. C. (2009). Cardiovascular response to interpersonal provocation and mental arithmetic among high and low hostile young adult males. Applied Psychophysiology and Biofeedback, 34, 2735.

Hutchinson, J. G., \& Ruiz, J. M. (2011). Neuroticism and cardiovascular response in women: evidence of effects on blood pressure recovery. Journal of Personality, 79(2), 277-302.

Jamner, L. D., Shapiro, D., Goldstein, I. B., \& Hug, R. (1991). Ambulatory blood pressure and heart rate in paramedics: Effects of cynical hostility and defensiveness. Psychosomatic Medicine, 51, 285-289.

Jorgensen, R. S., \& Kolodziej, M. E. (2007). Suppressed anger, evaluative threat, and cardiovascular reactivity: a tripartite profile approach. International Journal of Psychophysiology, 66(2), 102-108.
Jorgensen, R. S., \& Thibodeau, R. (2006). Defensive Hostility and Cardiovascular Disease: Theoretical and Empirical Bases for an Interpersonal ApproachAvoidance Conflict Perspective. In E. Molinari, A. Compare \& G. Parati (Eds.), Clinical Psychology and Heart Disease (pp. 217-232). New York: Springer.

Jorgensen, R. S., Abdul-Karim, K., Kahan, T. A., \& Frankowsi, J. J. (1995). Defensiveness, cynical hostility and cardiovascular reactivity: A moderator analysis. Psychotherapy and Psychosomatics, 64(3-4), 156-161.

Kelsey, R. M. (1993). Habituation of cardiovascular reactivity to psychological stress: Evidence and implications. In J. Blascovich \& E. S. Katkin (Eds.), Cardiovascular Reactivity to Psychological Stress and Disease (pp. 135-153). Washington, D.C.: American Psychological Association.

Larson, M. R., \& Langer, A. W. (1997). Defensive hostility and anger expression: relationship to additional heart rate reactivity during active coping. Psychophysiology, 34, 177-184.

Mente, A., \& Helmers, K. F. (1999). Defensive hostility and cardiovascular response to stress in young men. Personality and Individual Differences, 27(4), 683694.

Olson, M. B., Krantz, D. S., Kelsey, S. F., Pepine, C. J., Sopko, G., Handberg, E., Rogers, W. J., Gierach, G. L., McClure, C. K., \& Merz, C. N. (2005). Hostility scores are associated with increased risk of cardiovascular events in women undergoing coronary angiography: a report from the NHLBI-Sponsored WISE Study-. Psychosomatic Medicine, 4, 546-52.

Palmero, F., Breva, A., \& Espinosa, M. (1994). Efectos psicofisiológicos del estrés real y ficticio en sujetos Tipo A y sujetos Tipo B. Anales de Psicología, 10, 157-165.

Palmero, F., Breva, A., \& Landeta, O. (2002). Hostilidad defensiva y reactividad cardiovascular en una situación de estrés real. Ansiedad y Estrés, 8(2-3), 115142.

Palmero, F., Iñiguez, C., Guerrero, C., Carpi, A., Díez, J. L., \& Diago, J. L. (2007). Hostilidad, psicofisiología y salud cardiovascular. Avances de Psicología Latinoamérica. Colombia, 25(1), 22-43.

Palmero, F., \& Guerrero, C. (2012). Psychophysiological cardiovascular functioning in hostile defensive women. In D. C. Gaze (Ed.), The Cardiovascular System. Physiology, Diagnostics and Clinical Implications (pp. 465-478). Croacia, Rijeka,: Intech.

Shapiro, D., Goldstein, I. B., \& Jamner, L. D. (1995). Effects of anger/hostility, defensiveness, gender, and family history of hypertension on cardiovascular reactivity. Psychophysiology, 32, 425-435.

Shcheslavskava, O. V., Burg, M. M., McKinley, P. S., Schwartz, J. E., Gerin, W., Ryff, C. D., Weinstein, M., Seeman, T. E., \& Sloan, R. P. (2010). Heart rate recovery after cognitive challenge is preserved with age. Psychosomatic Medicine, 72(2), 128-133.

Shimbo, D., Chaplin, W., Kuruvilla, S., Wasson, L. T., Abraham, D., \& Burg, M. M. (2009). Hostility and platelet reactivity in individuals without a history of cardiovascular disease events. Psychosomatic medicine, 71(7), 741-747.

Sloan, R., Shapiro, P. A., Gorenstein, E. E., Tager, F. A., Monk, E. C., McKinley, P. S., Bagiella, E., Chen, I., Steinman, R., Myers, M. M., \& Bigger, J. T. (2010). Cardiac autonomic control and treatment of hostility: A randomized controlled trial. Psychosomatic Medicine, 72, 1-8.

Steptoe, A., Cropley, M., \& Joekes, K. (2000). Task demands and the pressures of everyday life: Associations between cardiovascular reactivity and work blood pressure and heart rate. Health Psychology, 19, 46-54.

Vella, E. J., \& Friedman, B. H. (2009). Hostility and anger-in: Cardiovascular reactivity and recovery to mental arithmetic stress. International Journal of Psychophysiology, 72, 253-259.

Vella, E. J., \& Friedman, B. H. (2007). Autonomic characteristics of defensive hostility: Reactivity and recovery to active and passive stressors. International Journal of Psychophysiology, 66, 95-101.

World Health Organization (2013). Cardiovascular disease. Controlling high blood pressure. Retrieved from http://www.who.int/cardiovascular diseases/en/

(Article received: 20-09-2012; revised: 05-11-2013; accepted: 06-11-2013) 